Portland State University

PDXScholar

$5-21-2021$

\title{
CONNECTION, COMPASSION, and HONESTY: Using Picture Books to Help Build a Healthier Relationship to Death in a Death-Denying Culture
}

Kami Sahalie Upshaw Gould

Portland State University

Follow this and additional works at: https://pdxscholar.library.pdx.edu/honorstheses

Part of the Children's and Young Adult Literature Commons, Family, Life Course, and Society Commons, Graphic Design Commons, and the Illustration Commons Let us know how access to this document benefits you.

\section{Recommended Citation}

Gould, Kami Sahalie Upshaw, "CONNECTION, COMPASSION, and HONESTY: Using Picture Books to Help Build a Healthier Relationship to Death in a Death-Denying Culture" (2021). University Honors Theses. Paper 1085.

https://doi.org/10.15760/honors.1112

This Thesis is brought to you for free and open access. It has been accepted for inclusion in University Honors Theses by an authorized administrator of PDXScholar. Please contact us if we can make this document more accessible: pdxscholar@pdx.edu. 
CONNECTION, COMPASSION, and HONESTY:

Using Picture Books to Help Build a Healthier Relationship to Death in a

Death Denying Culture

By

Kami Sahalie Upshaw Gould

An undergraduate honors thesis submitted in partial fulfillment of the requirements for the degree of

Bachelor of Science

in

University Honors

and

Graphic Design

Thesis Adviser

Meredith James 


\begin{abstract}
This paper explores the ways children are taught about death and dying and how children's picture books can be utilized in difficult conversations of this nature. I go into the historical advent of books specifically for children and research how different ways of explaining death can help or hurt a child. Through this research, I explore how our situationality in a death denying culture has shaped how we explain death to children and what steps can be taken to counter this denial.
\end{abstract}




\section{Introduction}

I formed my thesis project around how storytelling and picture books can help to build a healthier relationship to death and dying among children. My original thesis evolved into how children learn about death, how it is discussed in American society, how our current attitudes towards death fail us, and how children's picture books portray death.

\section{Research Summary}

\section{Death Culture}

Attitudes towards death can be sorted into 3 separate categories: death accepting, death fearing, and death denying (13). People who navigate life with a death accepting attitude are far more likely to deal with death in their own lives in a healthier, less damaging way and are more likely to recover quickly from a loss using effective coping mechanisms while grieving. Individuals and societies with a death fearing attitude are fully aware of the presence and inevitability of death but, unlike death accepting cultures, use this inevitability as a rationale for fear-based practises intended to avoid death at all costs. The most common American attitude towards death has been informed largely by our puritanical past and our current adulation of medical technology; we deeply fear death yet are not taught to speak openly about it, which places us in the death denial category (9). Our media depicts death as something optional, a plot device that can be fought against by protagonists and the power of medical technology. Western medicine itself has become a death denying practice, as it focuses on 
life-prolonging technology and treats death not as an inevitable conclusion to everyone's life, but as something that can be overcome if one simply fights hard enough. These attitudes towards death not only serve to muddy the already difficult-to-traverse waters of grief, but keep death as something 'polite society' doesn't openly discuss (12). This secrecy and denial makes a horribly upsetting experience all the more harmful. In response to the death denial of American culture, I wanted to create a book that showed a young child experiencing grief in a public, honest, liberated way. I chose to write and illustrate a children's book for two reasons. One, I am interested in the children's book industry as a possible career. Two, to build a healthier response to death, it made logical sense to try and start from the beginning and offer children a foundation for how they think about death in their very early lives.

The vast majority of media, even children's media, reflects and reinforces the social mores of the society it is made in. American culture since the end of World War II can be classified as 'death denying' (13) so it follows that our media would reinforce fear and wilful ignorance when it comes to death. With children's media, the rationale is often that by keeping children in the dark about death and dying, or using flowery language and metaphors to soften the blow, adults are protecting children from a difficult reality and smorgasbord of complicated emotion. In reality, research suggests that this is just creating another generation of people who don't know how to talk about death and, thus, are unable to process it in a healthy way (11). 


\section{Children's Books and their Approach to Death}

Picture books can effectively introduce difficult or complex subjects to young children in an age-appropriate manner. Books formulated particularly for children are a fairly new invention, gaining mainstream popularity in the 20th century and, before the 50's, primarily dealing with religious indoctrination and functional training of a child (9).

For most of Western history, children were only read the Bible or other religious texts, which were not in any way abridged to be made more appropriate for a young audience. Towards the early 1800's, English publishers began making books specifically for children, with pictures and easy-to-follow narratives (10). Though this was an important step towards creating the genre of Children's Literature, these books were wholly focused on how to indoctrinate children to Christianity from the earliest possible age. For much of history, children's books took up the mantle of religious education. This viewpoint was most marked in children's books about death and dying, as the fate of a character after dying was explained in certain terms (they went to heaven, the met their maker), and it was not until the 1960's that children's books took a decidedly secular turn, one which has continued to the present day (10). Scholarly research suggests that a secular approach allows a child the most developmentally appropriate tools to deal with mortality, while adding concepts of heaven and hell only serve to confuse them(7).

Children's books that use straightforward, non-religious or non-metaphorical language to talk about death and dying are the most effective and offer the clearest explanation for children. In my primary research, religion had not been seen as a positive influence in education about mortality. Instead, everyone I surveyed spoke 
about the value of openness and honesty and reported that being told, unequivocally, there was or was not a heaven or hell was the most harmful thing they remembered when being taught about death (1). A couple people mentioned that they felt like being told what others believed and being asked what rang true to them as individuals would have been the best way to broach this subject (1).

The interviews and survey I conducted were pleasantly surprising in many ways; the biggest surprise to me was how willing people were to delve into deeply personal, vulnerable answers when asked about death. My in-person interviews all took around 1 to 2 hours, and most of that time was spent by my interviewee talking at length about their experiences with death and dying, what they'd been taught as children, and how they felt our cultural attitude towards death could be improved. In my survey, over 30 people responded, most of whom spent a good amount of time writing out long paragraphs of self reflection and analysis. This large response not only gave me a huge amount of information to work with, but also reinforced why I think this project is necessary.

\section{Audience}

Picture books and children's literature pose an interesting and wholly unique challenge; because children don't hold any purchasing power, they are not the only audience you must consider. In order to make a successful children's book, an author must make something which appeals both to the child and to the adult purchasing the book (7). In my case, I have formulated a book about death that challenges societal norms and 
offers an alternative view of death for children, yet is also approachable to the adults in their lives. I am focusing on children who fall into the Early Reader category, which is ages 6 to 9 . This means the book should be narratively interesting and complex enough to hold up under repeated readings with a parent or guardian, while still being simple enough that a child could eventually read it to themselves.

Initially, I was considering making a book specifically for children who had recently experienced a death, but after my primary research I decided a more useful and universally needed book would cover the concept of death for all children and could be used not only after a child has experienced loss, but as a way to introduce and normalize the topic before it was ever experienced first hand.

My secondary audience is the people who hold purchasing power; parents, guardians, and librarians. In a bookstore setting, picture books are filtered by what the parent or guardian thinks the child would enjoy and benefit from, leaving the ultimate decision-making up to the adult. In a library setting, children are more in control of choosing books for themselves as there isn't the concern of money, but a librarian still needs to decide to buy a book for the library in the first place. This unique combined audience poses a problem I haven't faced in my design work before and it has been an interesting journey towards making something with this multifaceted audience in mind. Based on my research and own personal experience, children are fairly accepting about death if they have not been taught otherwise. Ergo, if I was able to write solely for children, I would be fairly blunt and matter-of-fact. Because adults are choosing these books for the children in their lives, I tried to combat a lifetime of American death denial 
and make something that is palatable for the adult, while being matter-of-fact enough that the child will, hopefully, form a slightly more accepting view of death.

\section{Visual Narrative}

For this book I made many, many, many (many, many,) moodboards and explored a lot of (perhaps too many) visual styles. I was greatly inspired by my favorite picture books from childhood and the illustrations of Quentin Blake, Patricia Polacco, Michael Martchenko, Tommy Depaola, John Bauer and more. I wanted to lean into my strengths, color pairing and illustration, and place a heavy emphasis on these. I chose to depict the characters as humanoid but not human, specifically trolls, in order to leave out markers of race and hopefully make this book more relatable for a greater number of children. I wanted the characters to be slightly monstrous in order to pay homage to troll mythology, but to retain a cuteness and approachability that would allow the reader to immerse themselves further into the story. I also chose bright, poppy colors as my research indicated children were more drawn to books with bright colors and dynamic shapes.

Subconsciously, both main characters draw a strong resemblance to real life people. Papa Troll looks a lot like my grandpa (who he was partially based on) and Nina looks a little bit like me. This wasn't on purpose, but I noticed pretty early on what was happening and decided to go with it. As an illustrator, I struggle a lot with backgrounds and thus was pretty intimidated by the prospect of creating 12 different backgrounds! I tried to create environments that spoke both to the reader and to the trolls; slightly natural (ie. Nina's room) and human (ie. the living room scene). I ended up having a lot 
of fun with this part of the project and feel I learned a lot about creating great backgrounds and placing active characters into them.

\section{Written Narrative}

In writing this book I wanted to keep the findings from my research at the forefront of my mind. One of the most disturbing things to me was the finding that even in a genre and subject I thought would be exempt, gender roles and social norms are reinforced. Female characters are depicted in their grief in crying, silence, and introspection, while male characters primarily used anger to express their loss (8). This not only limits children's 'acceptable' responses to death, but also promotes a deeper indoctrination into gender norms and limiting self-expression. This particular finding made me want to create a female character that openly showed rage and destruction when faced with loss and grief. I made the main character female mainly because of this, though if I were to do this again I might try to create a character that had a more ambiguous gender in order to make them more accessible and place the focus on the emotions rather than the individual. In writing this book I drew on my own experience with death and tried to focus specifically on the things that I felt ashamed of in my own grieving process. One of the biggest inspirations to me was the children's book "Michael Rosen's Sad Book" by Michael Rosen, illustrated by Quentin Blake. In it, Michael Rosen depicts himself in the throes of grief after the death of his son and doesn't shy away from the grungier, weirder, at times embarrassing, aspects of being in grief. This was something I wanted to do in my own way in my book, so I focused on feelings of anger, emptiness, and powerlessness. 
I chose to write about two characters, a childlike troll (Nina) who in my mind is around 8 or 9 , though this is never explicitly said, and an ambiguous father figure (Papa Troll). I chose to make the characters humanoid but not human in order to prevent identifiers of race, hopefully helping a greater range of children to relate to it, and to add a shade of whimsy and abstraction to help soften the content. The book takes place a year after Papa Troll has died and explores Nina Troll's continued grief and complicated emotions as she navigates this new world without Papa Troll in it. Unintentionally, I drew on elements of my father and grandfather in creating Papa Troll and he became an amalgamation of two important father figures in my own life. Throughout making this book, the similarities to people I love dearly made it much more emotional than most other design projects l've undertaken. Identifying habits, likes, and dislikes, were reserved only for Papa Troll. Nina Troll intentionally does not have any explicit likes and dislikes and the only times when her interests are made clear are as they relate to Papa Troll. I did this in the hope that she would be relatable to a large audience and that her main role as a character would be in illustrating a variety of strong emotions.

\section{Detailed Description}

What follows is a detailed description of certain artistic choices I made on specific pages of the book. Not every page is included, but the ones I feel are most important and/or exciting are explored. 


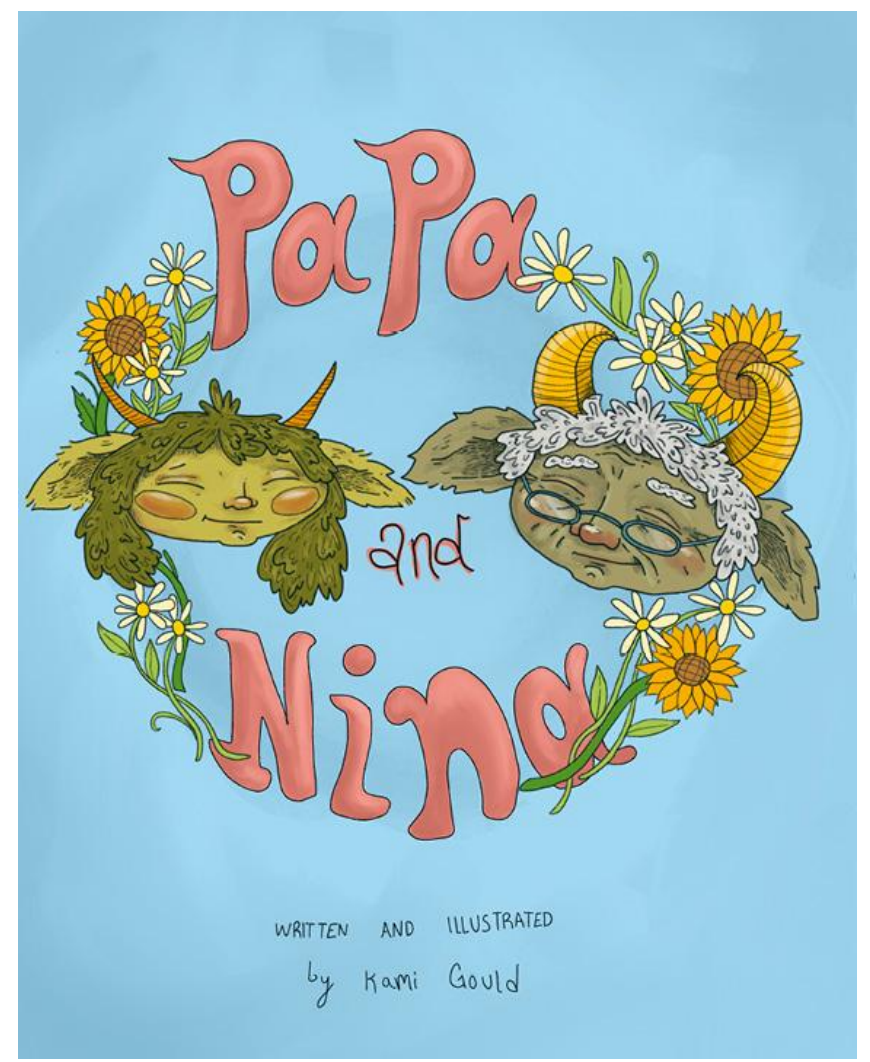

The cover is one of my favorite illustrations from this book. I wanted to make something that showed the soft side of Nina and Papa Troll and felt like a celebration of their relationship. 


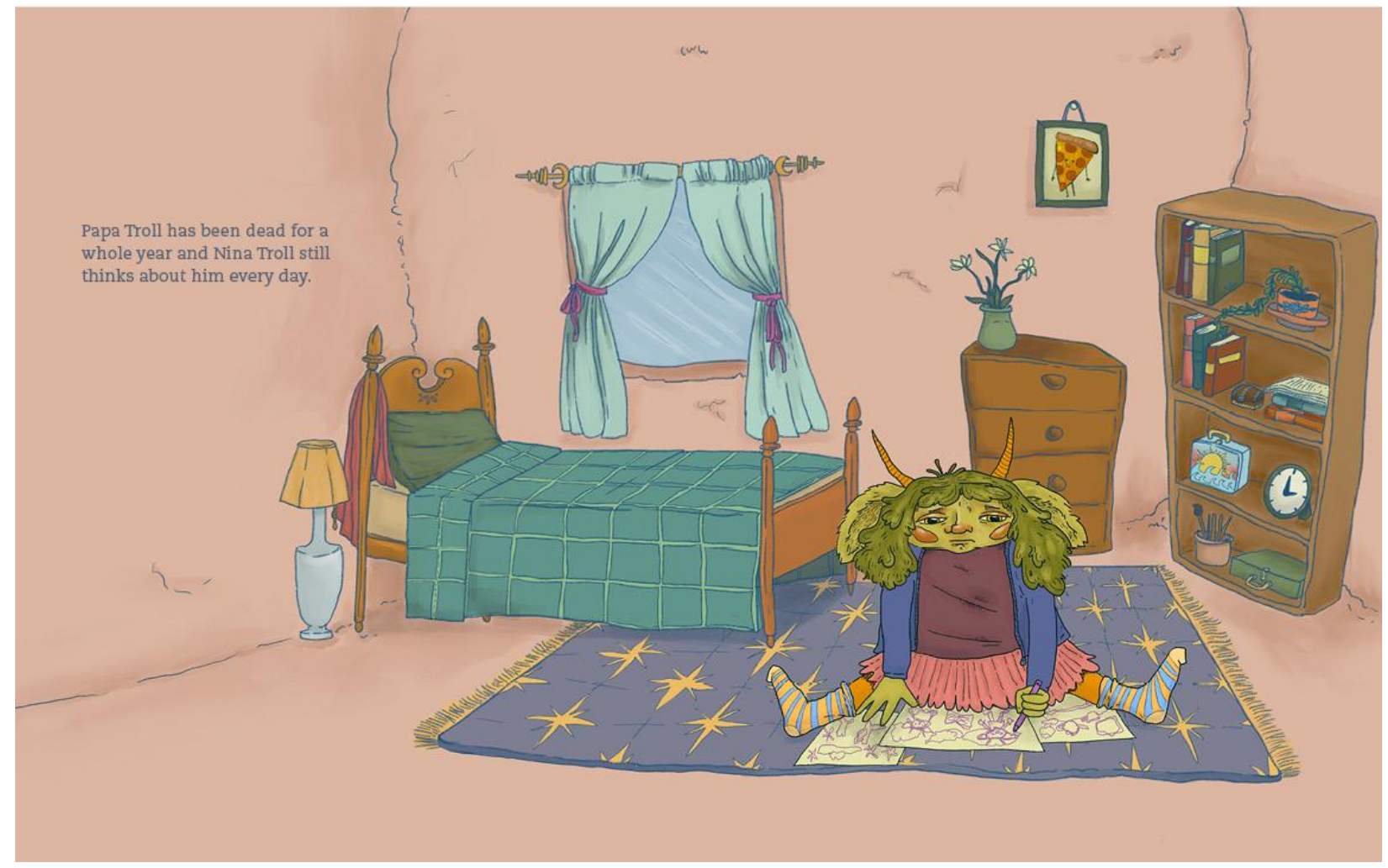

This spread is the first of the book. I used it to help solidify some of Nina's characteristics, set a scene and offer a setting to revisit later. I wanted her facial expression in this spread to look pensive and melancholy but not outright upset, expressing the evolution of grief as time goes on. 


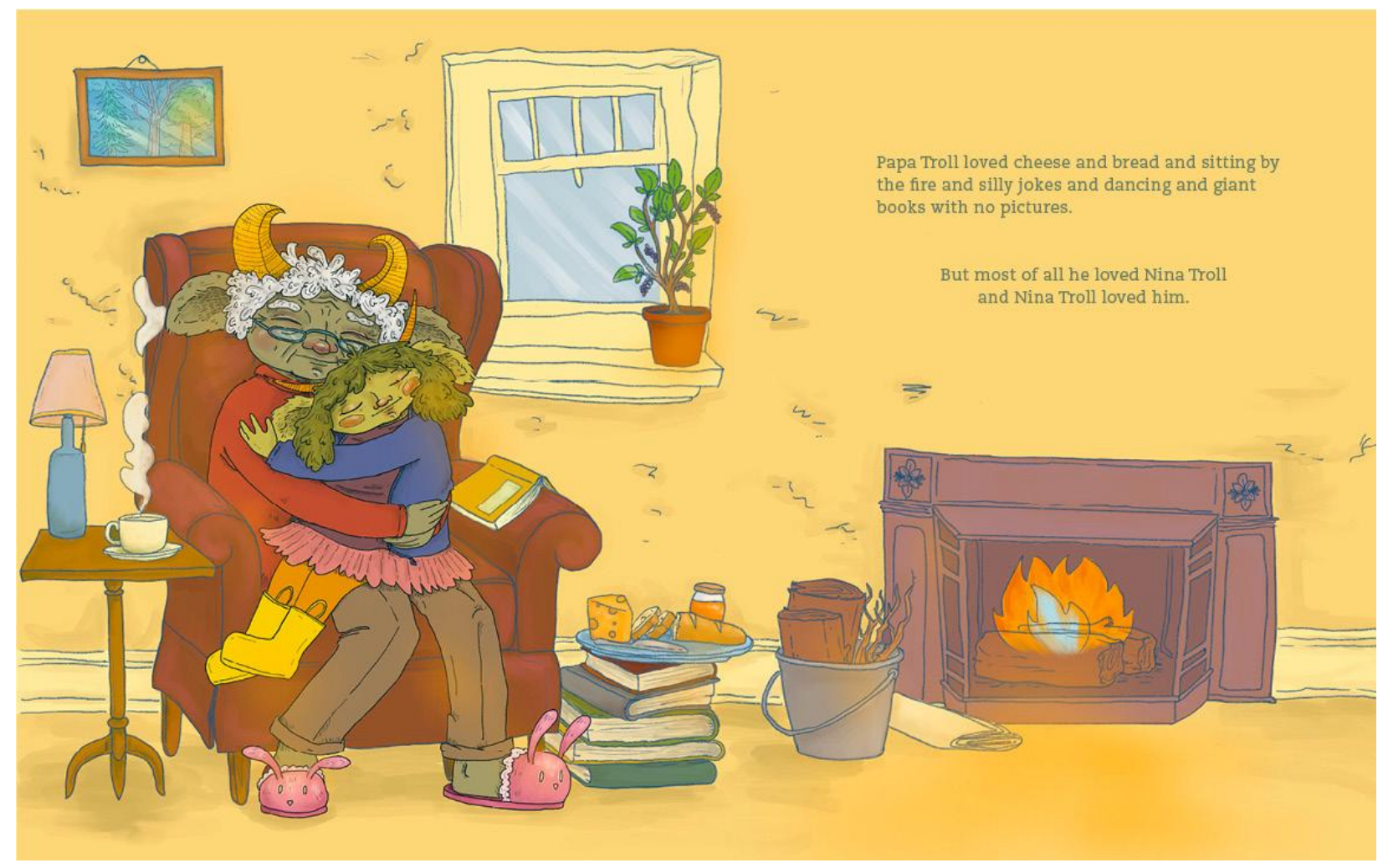

This spread is my favorite in the book; it's primary purpose is to illustrate the value of Papa and Nina's relationship, the comfort and safety they had with each other and the gravity of this loss. This spread was largely informed by my own family and I used warm colors and soft lighting to create as cozy a setting as possible. 


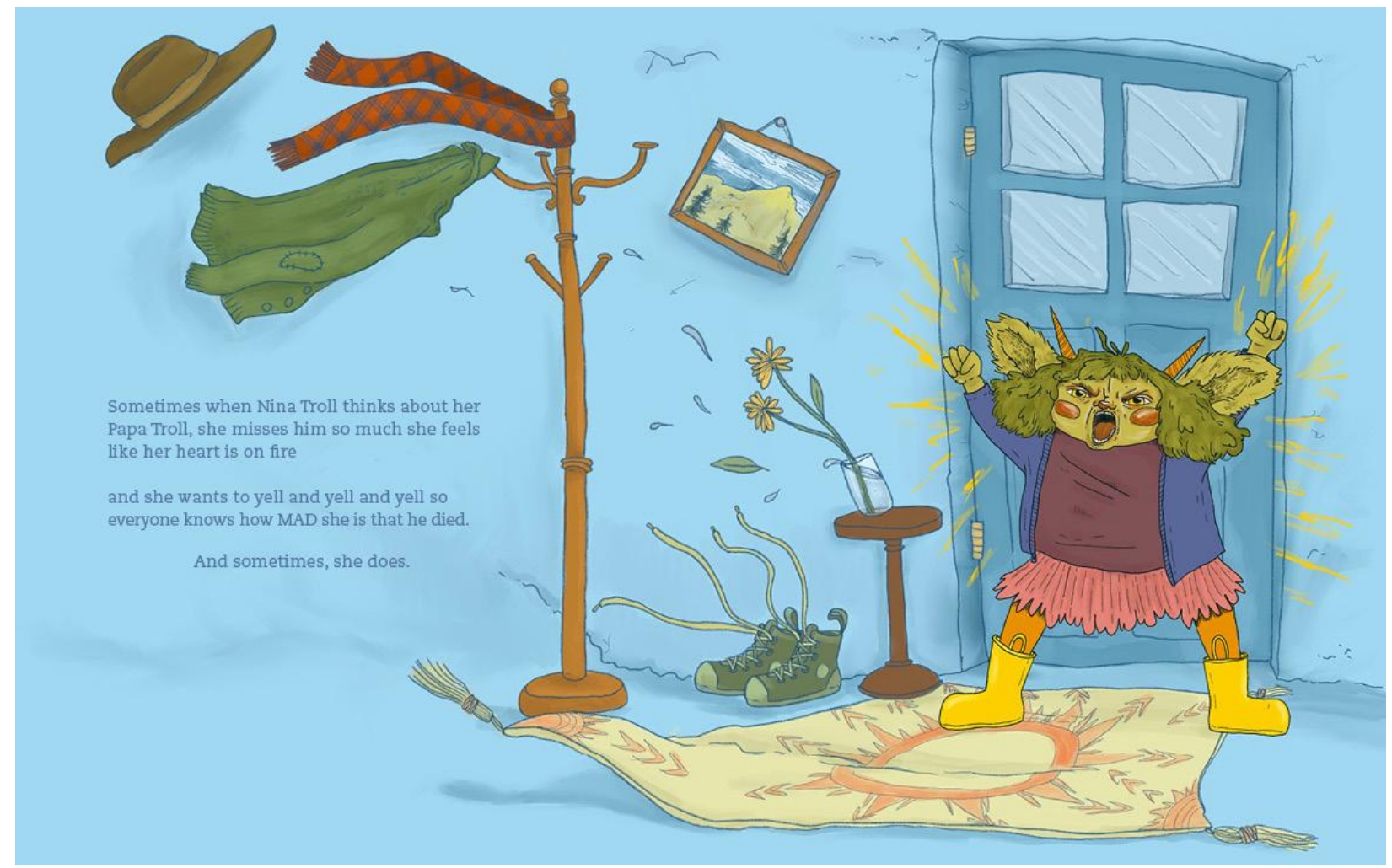

Displaying Nina in the throes of rage was very important to me from the beginning of this process. Focusing on the more destructive side of grief and offering examples of how it can affect people was intended to offer children some explanation for behaviors they might feel ashamed or guilty of. 


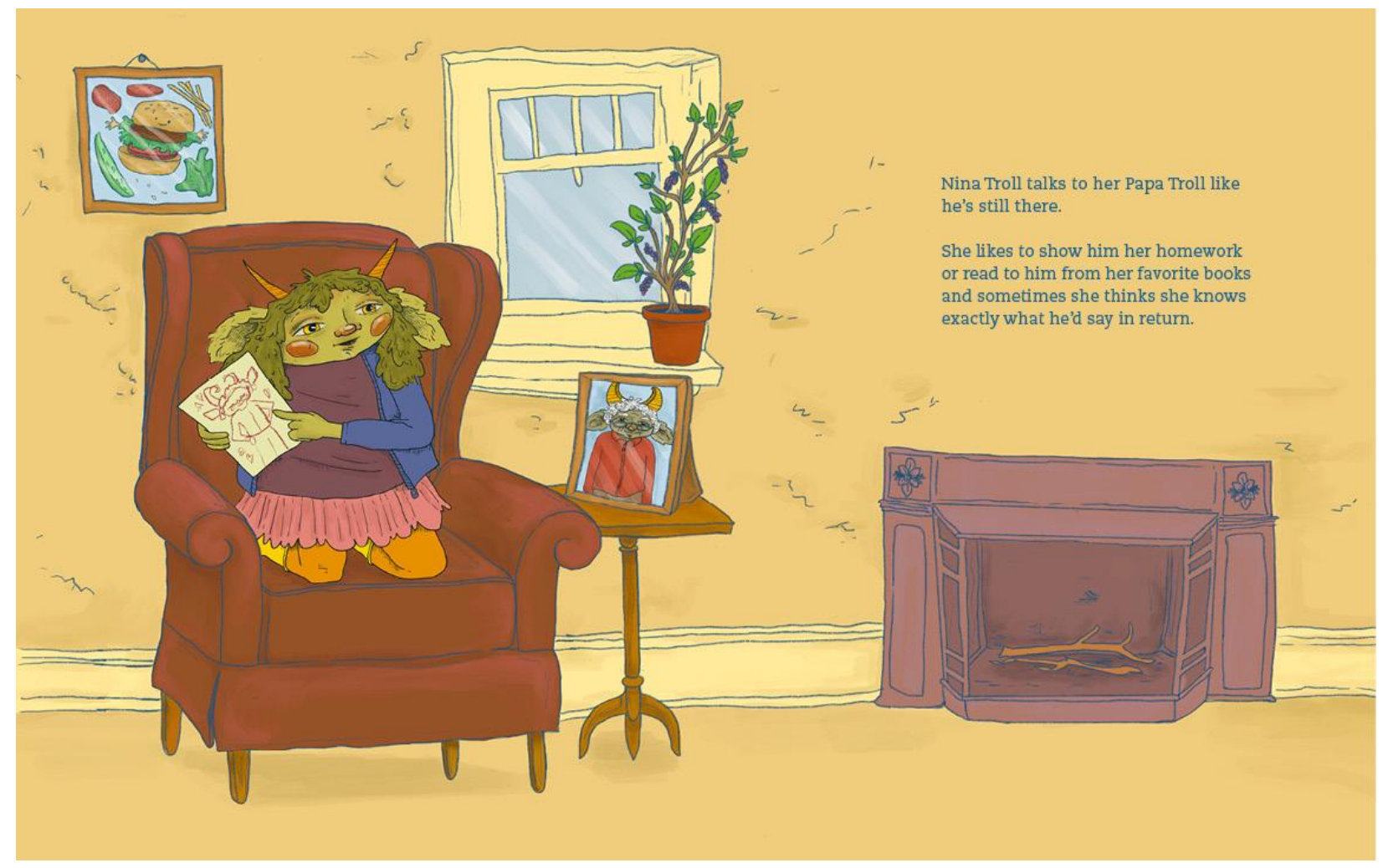

This spread shows Nina returning to the setting of a previous spread which has evolved as time passed since Papa Troll died. It is a setting of great importance as it is where the reader is first introduced to Papa Troll and clearly holds great importance for Nina as well. This spread is meant to serve as a way for the reader to identify how things have changed since Papa Troll died, but with a poignant rather than depressing feeling, as we are also able to see how Nina has evolved and begun to make peace with Papa Troll's death. This page also exemplifies a behavior known to help process grief, that of talking to the deceased person as if they were still there (12). 


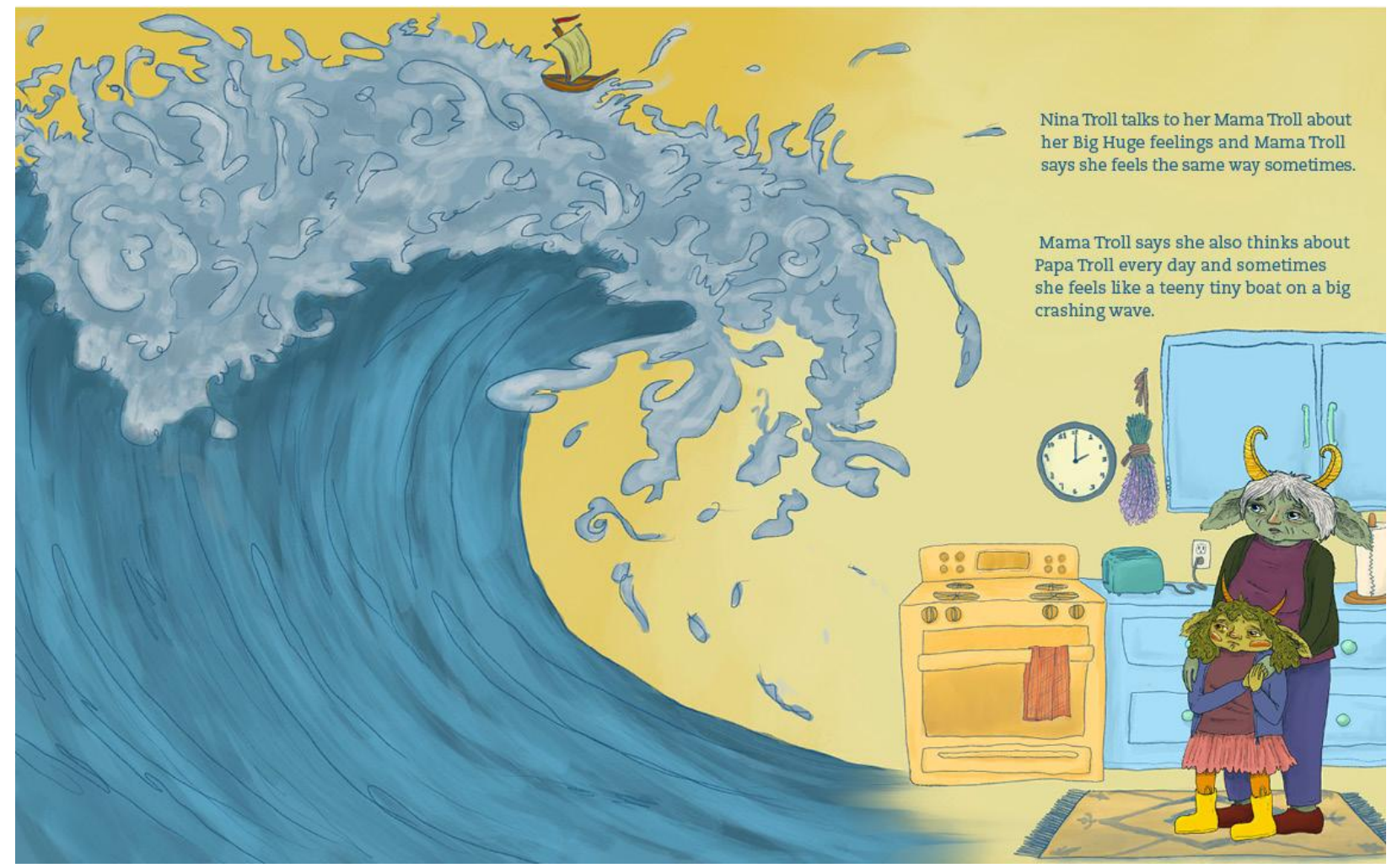

This spread expresses another behavior I wanted to normalize for children; talking to trusted friends and family about the 'big huge' feelings of grief they may be experiencing. 


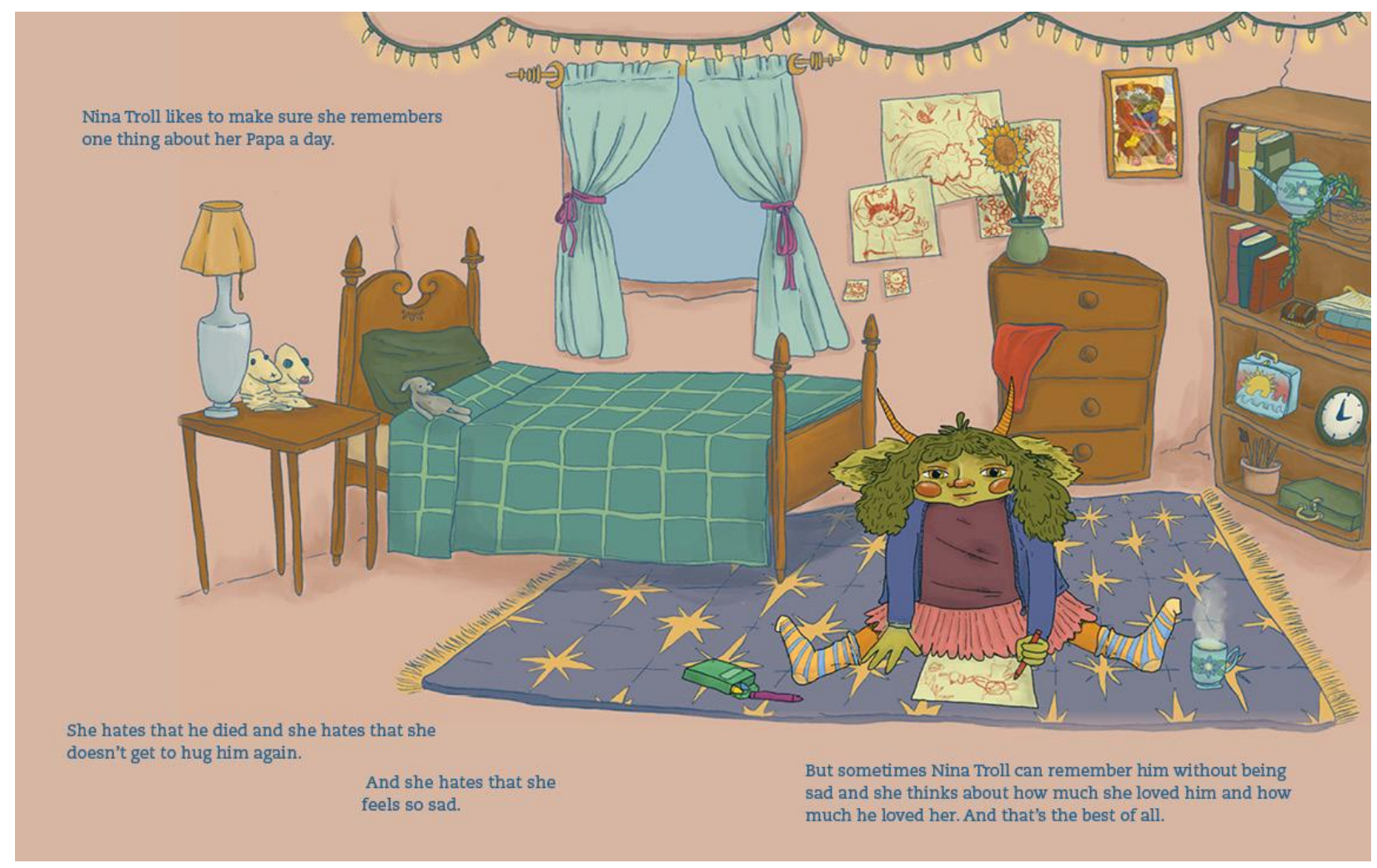

The final spread mirrors the first spread, with a few minor details and some notable differences in Nina's expression. I changed the pictures on the wall behind Nina to reflect her processing of the events described in the book. There is also a new picture of Nina and Papa Troll sharing their special chair. I wanted to make Nina look happy, in a soft way, but overall positive, leaving the reader with a slight uplift at the end of the book and the idea that huge feelings of grief can be worked through and mostly made peace with over time. 


\section{Conclusion}

This project helped me learn so much in such a short amount of time. It opened my eyes to a decades-long effort by activists, academics, and death professionals towards a more equitable, loving, accepting mode of death in the United States. I learned about my own struggles as an author and illustrator and became aware of the ways, though I may try to pretend otherwise, that American death denial has shaped my own reality. Though I plan to redo and rework many of the pages from this book before exploring publishing, the process of creating it helped me suss out my own personal style and the style I want to continue working on. 


\section{Sources}

1. Gould, K (2020) Thesis Survey

2. Gould, K (November 9, 2020) Interview with Isabel McTighe

3. Gould, K (November 14, 2020) Interview with Reverend Hugh Gould

4.Gould, K (November 20, 2020) Interview with Sarah Pattee L.P.C.

5. Gould, K (November 20, 2020) Interview with Laramie Holliman R.N.

6. Gould, K (November 17, 2020) Interview with Brita Gould

7. Gould, K (November 16, 2020) Interview with Dennis Gould

8. Gould, K (November 14, 2020) Interview with Brianna Rosen

9. Gibson, L. R., \& Zaidman, L. M. (1991). Death in Children's Literature: Taboo or Not Taboo? Children's Literature Association Quarterly, 16(4), 232-234. doi:10.1353/ chq.0.0855

10. Sadler, D. (1991). "Grandpa Died Last Night": Children's Books about the Death of Grandparents. Children's Literature Association Quarterly, 16(4), 246-250. doi:10.1353/ chq.0.0802

11. Moore, T. E., \& Mae, R. (1987). Who Dies and Who Cries: Death and Bereavement in Children's Literature. Journal of Communication, 37(4), 52-64.

doi:10.1111/j.1460-2466.1987.tb01008.x

12. Jenkinson, S. (2017). Die Wise: A Manifesto for Sanity and Soul. North Atlantic Books. 
13. Doughty, C. (2020). Will my Cat Eat my Eyeballs?: Big questions from tiny mortals about death. London, England: Weidenfeld \& Nicolson.

14. Tan, S. (2020). The Red Tree. Glen Huntly, VIC: Story Box Library.

15. Rosen, M., \& Blake, Q. (2011). Michael Rosen's sad book. London, England:

Walker. 